\title{
Vacuna anti-Haemophilus influenzae de tipo b (Hib) en el Calendario Nacional de Argentina: portación nasofaríngea de Hib tras 8 años de su introducción
}

\author{
VIVIANA ROMANIN ${ }^{1}$, LAURA CHIAVETTA ${ }^{2}$, MARÍA C. SALVAY ${ }^{1}$, \\ MARÍA J. CHIOLO ${ }^{3}$, MABEL REGUEIRA ${ }^{2}$, ADRIANA BARRIOS ${ }^{2}$, \\ GLORIA CALIFANO $^{3}$, SALVADOR GARCÍA ${ }^{4}$, ANGELA GENTILE ${ }^{1}$ \\ 1. Hospital de Niños "Dr. Ricardo Gutiérrez". \\ 2. Instituto Nacional de Enfermedades Infecciosas "Dr. Carlos Malbrán". \\ 3. Hospital de Niños "Dr. Pedro de Elizalde". \\ 4. Organización Panamericana de la Salud (OPS). Ciudad de Buenos Aires.
}

\begin{abstract}
Nasopharyngeal Colonization (NC) by Haemophilus influenzae: 8 years after the introduction of the Haemophilus influenzae type b vaccination in the Argentine National Schedule

Introduction: As a part of the PAHO supported protocol "Evaluation of the impact of Haemophilus influenzae $b$ vaccination programs in four Latinamerican countrys", a study took place in Argentine 8 years after introduction of Hib vaccine. Objective: To evaluate the impact of Hib vaccination measuring Nasopharyngeal Colonization (NC) rate and to identify factors associated to Haemophilus influenzae (HI) carrier status. Methods: Cross-sectional study -from June $27^{\text {th }} 2005$ to April 12 $12^{\text {th }}$ 2006- in two pediatric hospitals, HNRG and PE. Nasopharyngeal swab specimens were processed in the INEI-ANLIS "Dr. C. Malbrán"; samples were cultured in chocolate agar medium containing bacitracin. Hi was identified with technics of Gram, oxidase, catalase, growth factors $(\mathrm{V}-\mathrm{X}-\mathrm{XV})$ and test of porphyrin. Capsular serotypification was made by agglutination in lamina with specific antisera and the confirmation by polymerase chain reaction. Population: 900 children of 1 year of age, vaccinated with 3 doses and 700 children of 5 years, with 4 vaccine doses. Results: Hi was detected in 40\% (641/1.600) of samples, among Hi, 4,8\% (31/641) were encapsulated ( 3 serotypes a, 1 b, 3 c, 5 d, 7 e, and 12 f). Only one child of 1 year was NC carrier of Hi type b $(0.06 \%)$.Conclusions: We found a very low NC Hib $(0.06 \%)$ rate, for this reason associations could not be analyzed. The age, household and day care center contacts were associated with NC by Haemophilus influenzae.
\end{abstract}

(Key words: Haemophilus influenzae type b; Nasopharyngeal colonization; Vaccination). Arch Argent Pediatr 2007; 105 (6): 498-505/498

\section{Correspondencia a:}

Viviana Romanin

E-mail:vromanin@arnet.com.ar

La idea original y la confección del Protocolo, estuvieron a cargo de la Organización Panamericana de la Salud.

El Protocolo fue aprobado por los Comités de Docencia e Investigación y Bioética, de los hospitales de Niños "Dr. Ricardo Gutiérrez" y "Dr. Pedro de Elizalde". 


\section{RESUMEN}

Introducción: En el contexto del "Protocolo para una evaluación del Impacto de los Programas de Vacunación contra Haemophilus influenzae tipo b, en cuatro países latinoamericanos" auspiciado por la OPS, se efectuó un estudio en Argentina luego de 8 años de introducción de la vacuna anti-Hib. Objetivos: Estimar el impacto de la vacunación anti-Hib mediante la evaluación de la tasa de portación nasofaríngea. Identificar factores asociados a la portación de Haemophilus influenzae. Métodos: Estudio de corte transversal, junio 2005- abril 2006, en el Hospital de Niños "Dr. Ricardo Gutiérrez" y el Hospital de Niños "Dr. Pedro de Elizalde". Las muestras de hisopado nasofarígeo se procesaron en el INEI-ANLIS "Dr. Carlos Malbrán", se realizó cultivo en agar chocolate con bacitracina, se identificó $H$. influenzae mediante Gram, oxidasa, catalasa, requerimiento de factores y prueba de la porfirina. La serotipificación capsular se realizó por aglutinación en lámina con antisueros específicos y su confirmación por reacción en cadena de la polimerasa. Población: 900 niños de 1 año y 700 de 5 años, con 3 y 4 dosis de vacuna, respectivamente. Resultados: Hi se detectó en el 40\% (641/1.600) de las muestras; entre los $\mathrm{Hi}, 4,8 \%$ (31/641) fueron capsulados. Los Hi capsulados fueron: 3 serotipo a, 1b, 3c, 5d, 7e y 12f. Sólo un niño de 1 año fue portador de Hib (tasa $=0,06 \%$ ). Los factores asociados a la portación de Hi fueron: la edad, convivir con algún hermano menor de 18 años y concurrir a jardín maternal. Conclusiones: Se halló una tasa de portación nasofaríngea de Hib muy baja, de $0,06 \%$; por ello, no se pudieron analizar asociaciones. La edad, los contactos familiares y los extradomiciliarios se asociaron con la portación de Haemophilus influenzae. (Palabras clave: Haemophilus influenzae b; Portación nasofaríngea; Vacunación). Arch Argent Pediatr 2007; 105 (6): 498-505/498

ESTE TRABAJO LO PUEDE ENCONTRAR EN EXTENSO EN WWW.SCIELO.CL 